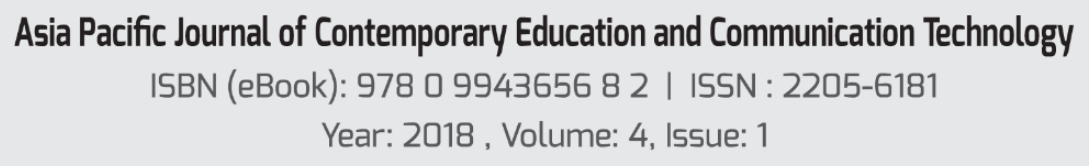

\title{
THE IMPACT OF RELIGION ON ARABIC LANGUAGE MAINTENANCE AMONG MEMBERS OF THE ARABIC-SPEAKING COMMUNITY IN THE REGIONAL CITY OF TOOWOOMBA, AUSTRALIA
}

\author{
Mostefa Abdelhadi \\ University of Southern Queensland, Australia \\ Email: mostefaabdelhadi@yahoo.com.au
}

\begin{abstract}
This paper attempts to explore the role that religion plays in the maintenance of the Arabic language within the Arabic-speaking community in the regional Queensland city of Toowoomba, Australia. A qualitative approach was utilized in order to explore the language maintenance phenomenon through engaging in the everyday life of the Arabic speakers. Data was collected through participant observations and in-depth semi-structured interviews with 20 adults who were selected using a mixed purposeful sampling strategy. The findings of this study revealed that religion is an indicator for the maintenance of Arabic language within the Arabic speakers in Toowoomba. The conclusions of this study are envisaged to enrich the knowledge and theories of language maintenance, as well as redesigning the multilingualism and multiculturalism structure of the Australian society.
\end{abstract}

Keywords: Language Maintenance, Religion, Community Language, Arabic-Speaking Community.

\section{Introduction}

Australia has always been recognized by its linguistic and cultural diversity practised by the Indigenous inhabitants. It is reported that there were more than 600 Aboriginal and Torres Strait Islander languages during the British settlement in Australia (Hatoss, 2013). Unfortunately, most of these languages have disappeared and the number has diminished to only 150 languages, due to the settlers' conflict with the Indigenous people and the early death of indigenous people from epidemic diseases (Holmes, 2013), as well as assimilation pressures (Clyne, 1991). More recently, the linguistic situation in Australia has been entirely amended and reshaped with another 150 immigrant languages other than English brought by immigrants from all over the globe. In spite of such huge linguistic and cultural diversity, with over 300 languages spoken by Indigenous Australians and immigrants, Australia remains a mostly monolingual society where most of the population speaks English as the majority and de facto official language (Beykont, 2010; Holmes, 2013; Rubino, 2010).

On the basis of the 2011 Census of the Australian Bureau of Statistics (ABS), 81\% of the Australian population speak English at home, and this number has decreased slightly from $86 \%$ in 1986 (ABS, 2011). That implies that less than 20\% of people speak their native language at home, and this little number may alert us to the fact that some languages are on the edge of language shift in Australia. Statistics from the same census indicate that: (1) The majority of immigrants are gradually losing their original languages (ABS, 2011); (2) Australia policies are unsuccessful in encouraging the maintenance and transmission of the original language across generations (Hatoss, 2013); and (3) Multiculturalism policies have failed to protect and promote minority languages (Cavallaro, 2005).

The purpose of this study is to explore language maintenance efforts, experiences and challenges confronting the Arabic-speaking community in the regional city of Toowoomba, 
Australia, and to investigate the impact of the religion in the maintenance of Arabic language within this community.

\section{Literature Review}

A number of studies have investigated the maintenance of the minority languages all over the globe, notably in multilingual and multicultural societies (Clyne, 2005; Rubino, 2010). The aim behind these studies is linked to the advocacy and preservation of ethnic minority and immigrant languages from an unexpected shift or loss (Garcia, 2003). However, little research was undertaken on the maintenance of Arabic language among Arabic-speaking immigrants (Abdalla; 2006; Martin, 2009; Sehlaoui, 2008). These studies are reviewed in this literature to get comprehensive perspectives on the role of the religion in the preservation and maintenance of the Arabic language maintenance.

\section{The role of the religion towards Arabic language maintenance}

Research on language maintenance refers to the major role that religion can play in maintaining immigrant languages (Baker, 2011; Clyne \& Kipp, 1999; Clyne, 2005; Baker, 2011; Fishman 1991). For example, Baker (2011) points out that:

The religion can be a strong and important vehicle for the maintenance of a majority and a minority language. The use of classical Arabic in Islam, Hebrew in Judaism, and German among the Protestant Old Order Amish in Pennsylvania illustrates that religion can be a preserver of language (Baker, 2011, p. 57).

Similarly, Fishman (1991) referred to the role of religion in the maintenance of community languages. He reported that classical religious texts such as the Quranic Arabic, Prayer book and Old Testament, had successfully maintained intergenerational language maintenance and transmission.

In the same context, Baker (2011) contended that in Arab and Islamic countries, religion plays a significant role in restraining the expansion of English as a prestigious language and preventing it from penetrating a variety of domains.

Clyne \& Kipp (1999) did research into the use of Arabic among Australians of Egyptian and Lebanese background in Melbourne. They found that the Arabic language has a strong link to religion within the Muslim community, since the Qur'an was revealed in the Arabic language. Their results also indicated that the Muslim community had been successful in maintaining the Arabic language and transmitting it to their children through teaching and literacy. In their survey data, they confirmed that Arabic is better maintained by the second generation of Muslim Arabic speakers than by the second generation of non-Muslim Arabic speakers. The results indicated that religion is one of the motivating factors in maintaining the Arabic language.

A similar study was conducted by Gomaa (2011) about three Muslim families in Durham, UK. He found that Egyptian Arabic is well-maintained through weekend classes offered to Arab children by the Durham University mosque. The Durham University mosque does not teach children how to read and write in Arabic, but they do learn the verses of the Qur'an through memorization. According to the authors, religion is a driving force for the maintenance of the Arabic language among the Arabic speakers.

In contrast, Di Lucca, Masiero \& Pallotti (2008) conducted a study on Moroccan adolescents in Italy. They found that the religion did not play any motivating role in the maintenance of Arabic among Moroccans as they were undergoing a high shift towards the Italian language.

To sum up, the religion appears to be essential for the retention and transmission of the community language when it is in constant contact with the majority language. The religion has a great impact on intergenerational transmission of community languages. 


\section{Methodology}

\section{Participants}

In this qualitative study, the sample size was determined by the concept of saturation. The researcher was looking for the factors that may contribute to the maintenance of the Arabic language within the Arabic speaking community in the regional city of Toowoomba. The sample included 20 participants who were drawn purposefully from the community membership list at the Mosque.

A mixed purposeful sampling technique was used for recruiting 20 Arabic speakers from the mosque in the regional city of Toowoomba, Australia to participate in this study. First, the researcher conducted a purposive sampling technique at first in order to select 12 adult male participants from the membership list at the mosque. This list includes the population of about 1000 male adult individuals who are members of the mosque by paying annual membership fees. The Arabic speakers represent the majority at the Mosque.

The selection criteria for participation were: (1) adult first generation Arabic native speaker, (2) Arab in ethnicity, (3) married with at least one child. Secondly, eight female participants were recruited by a female research assistant using a snowballing technique. In this technique, each participant who agreed voluntarily to participate in this study was asked to identify other participants who met the selection criteria mentioned above and were willing to participate (Johnson \& Christensen, 2012). The snowballing technique was utilized due to the difficulty in finding female participants since they do not regularly come to the mosque. Additionally, there were other constraints such as the religious and cultural concerns among Arabic speakers. In view of that, the researcher was obliged to appoint a female research assistant to recruit, interview and observe female participants.

With respect to their age, the majority are in their 30s; there are only four in their 40 s and two in their late 20s. All the participants came to Australia in the last decade between 2006 and 2013. With regards to education, $90 \%$ of the participants were still students during the time the research was conducted. Among them, 35\% were undertaking Ph.D. studies, $35 \%$ a Master's Degree, 25\% a Bachelor of Arts Degree, and 5\% had a High School Certificate. A larger proportion came to study and subsequently preferred to settle down and live in Australia. However, there were only two male participants who were married to non-Arabicspeaking spouses. Their wives came from English-speaking countries: Australia and New Zealand.

\section{Data collection strategies}

Firstly, in order to answer the research questions, data were first gathered using in-depth, semi-structured interviews with the 20 Arabic speakers who met the sample selection criteria discussed in the "Participants" section. Secondly, in order to learn more about the participants' perspectives and experience, data were collected through observation in which the researcher observes and take field notes from the participants' interaction in order to form a better understanding of the central phenomenon.

\section{Ethical considerations}

Approval for this research was gained from the Human Research Ethics Committee (HREC) at the University of Southern Queensland, Australia. All ethical concerns about all aspects of this research were clearly explained to the participants verbally and it was also included in the participant information sheet as well as in the consent form. Participants in this study were informed that their contribution was entirely voluntary and they had the full right to withdraw at any stage during the study without any consequences. Participants were informed that their identity would be protected by providing a pseudonym rather than their actual names. 


\section{Data analysis procedures}

In the current study, the researcher adopted the same steps for analysing the data that are outlined in Creswell's (2014) plan of analysis. This plan involves going through several steps: (1) organizing and preparing data for analysis, (2) reading through all the gathered information in order to acquire a general sense of it, (3) coding the data by detecting text segments and giving a code label to them, (4) representing the data in tables or charts to convey information about each participant, and (5) making an interpretation of the data and comparing the findings with information found in literature (Creswell, 2014).The researcher found this plan to be very comprehensive and an easy way of dealing with the big amount of raw data gathered. A thematic analysis was utilized in this study, which involved going through all of the following steps: organising, transcribing and coding the data, to extract themes and sub-themes which would represent the findings of this study. Figure 1 is a summary of qualitative data analysis plan which refers to these steps starting at the bottom:

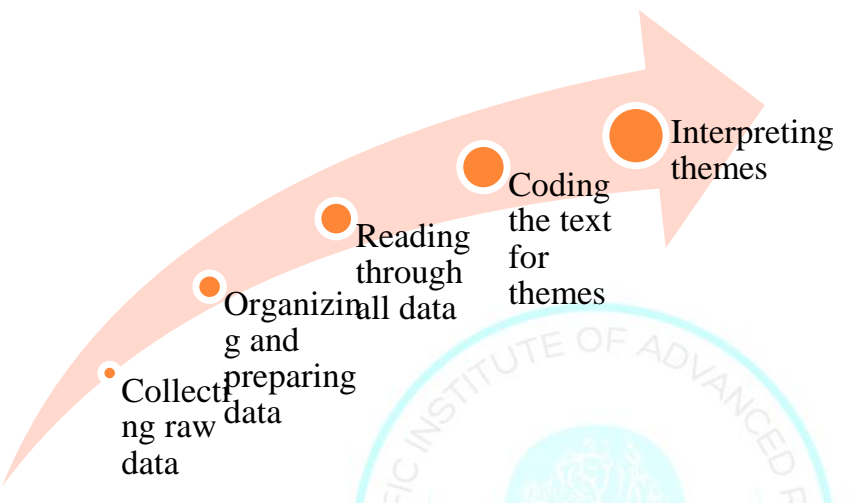

Figure 1: Qualitative Data Analysis Plan, Adapted from Creswell (2014)

\section{Findings}

This section describes the qualitative results that were uncovered through the use of in-depth semi-structured interviews and participant observations. The findings of this chapter are presented in two main sections: 1) general description of the sample, 2) description of the themes and sub-themes.

\section{General description of the sample}

The sample includes a total of 20 participants, 12 males and 8 females. This study did not intend to make a distinction or a comparison between male and female participants since there were no balanced samples, but rather to get a holistic understanding of the Arabic language maintenance from both genders' views.

Participants in this study came from different Arab countries, including the Middle East and North Africa. Seven were Libyan, six were Iraqi, two were Moroccan, two were Omani, one was Saudi, one was Kuwaiti, and one participant was Emirati. All participants were bilingual speakers of Arabic and English except for two participants who were multilingual. All the participants in this study were native speakers of Arabic, and Arab in ethnicity.

\section{Description of the themes and sub-themes}

The analysis of transcripts of both interviews and observations led to the emergence of several themes and sub-themes which contribute to the maintenance of Arabic among the Arabic-speaking community in the regional city of Toowoomba. In this section, the focus is on one theme which refers to the role of the religion in the maintenance of the Arabic language. 


\section{The impact of religion on Arabic language maintenance}

In response to the interview question: What role does the religion play in Arabic language maintenance?, participants described the impact of religion on the maintenance of their language. This theme is found to be one of the core factors that support the maintenance of Arabic language within the Arabic speaking community in the regional city of Toowoomba. This theme includes four significant sub-themes, as the participants perceived them: the role of religion, the role of the mosque and the benefits of Arabic and Quranic lessons. Figure 2 is a summary of this theme and its related sub-themes emerging from data analysis:

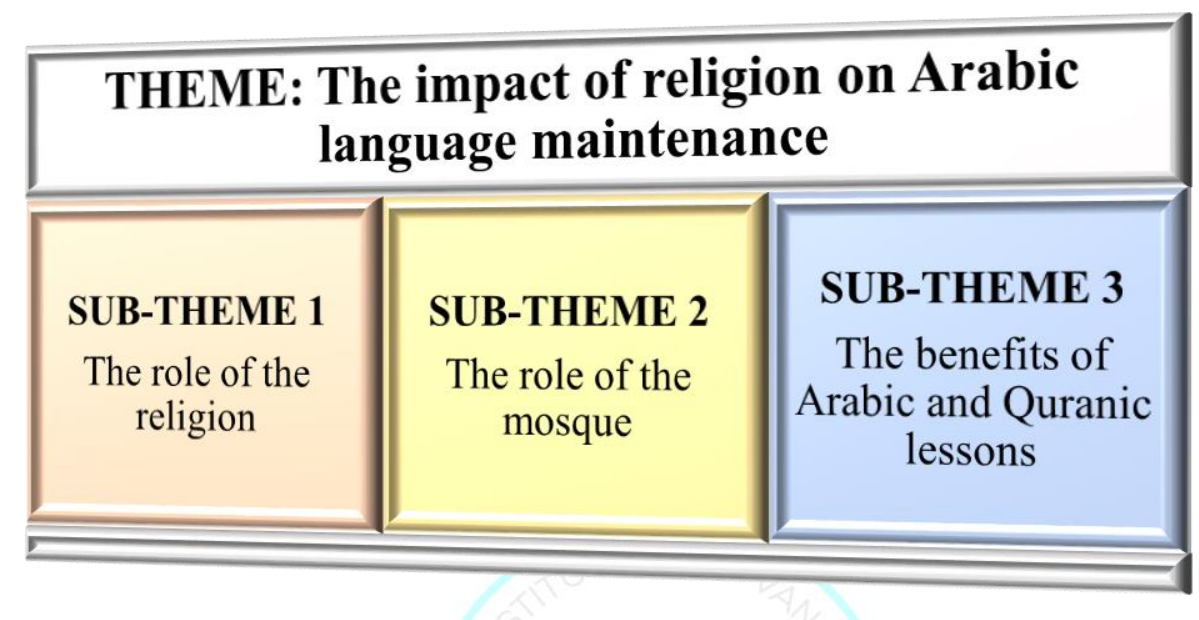

Figure 2: Major theme and its related sub-themes emerging from data analysis

\section{The role of the religion(Islam)- Theme 1, sub-theme 1}

All the participants referred to the importance of religion in the maintenance of Arabic. Their responses asserted the great influence of religion on the maintenance of the Arabic language. The following excerpt from one of the participants confirms this:

The Islamic religion has the Qur'an, which is an Arabic book, so the language is very important to understand and to do ah the religion, ah whatever they require you the religion and for that reason it is very important to know the Arabic so you can do whatever the Islam tell you to do. (S5M)

According to the Arabic speakers in this study, religion plays a critical role in maintaining language because it is the language of the Qur'an. Throughout the transcripts, all the participants talked about Arabic as the language of the Holy Qur'an. One of the participants said:

Yeah, you know when we speak of religion, we speak of the Qur'an. The Qur'an has been written and kept in Arabic, and so it will keep Arabic forever. The mosque is teaching the Qur'an. So my daughter and other children go there to learn the Qur'an and Arabic. (S2OF)

One of the participants admitted the importance of Arabic learning to understand the religion (Qur'an) and he mentioned that every Muslim has to know Arabic even if he or she is not an Arabic speaker:

Any Muslim will be very ashamed if he cannot read the Qur'an. Even I know many people from Indonesia, Malaysia, and India, they can recite the Qur'an very well, some of them did not understand what these words mean or these phrases meanings, but they can recite perfectly because they have already read the Qur'an when they are children, so they notice 
the Arabic because it is the basis... All the books related to the religion and the practice of Islam. (S2M)

One of the participants also noted that the religion encouraged all the Muslims to learn not just Arabic, the language of the Qur'an, but other languages as well. He said that:

Our religion actually, our religion always encourages us to learn different language not just keep one language, no. It encouraged us to learn a different language, why? Because we will be able to communicate with others, we will be able to understand others, yeah, it is not close to just Arabic, no, and there is a lot of encouragement, a lot of motivations to support us to learn other languages. (S9M)

All the comments made by the participants above expressed their views about the importance of the religion for all Arabs and Muslims in the world. All of them reported the firm connection between the Qur'an and the Arabic language. The latter is the language of the Qur'an, and this is one of the reasons that the participants wanted to maintain and preserve it for their children to be able to practise their religion.

\section{The role of the mosque - Theme 1, sub-theme 2}

The mosque plays a crucial role in the maintenance of the Arabic language in the Arabicspeaking community. All the parents' interview responses reflected the role of the mosque in keeping the community together. The following excerpts illustrate participants' views on the role of the mosque:

Yes, the mosque plays a major role in this regards, because you know, this is the place where all people are gathering there, and the place where this can be the umbrella for these types of activities rather than any other place because it is related especially to the language, Arabic language as well as their religion. (S2M)

The role of the mosque is a place of worship, and most of the performance of the prayers, here is getting done in Arabic, and only when it comes to making speech on Friday and stuff like that, the English language is present for translation but obviously the rest of the performance of the prayers done in Arabic. (S5M)

Based on analysis of the transcript, the mosque was not just a worship place, but also a place of learning and practising the Arabic language with other Arabic speakers from the community.

In addition to what has been said regarding the vital role of the mosque, two male participants expressed their thoughts about the role of the mosque and raised their concerns with regards to the teaching programs and the shortage of the lessons offered by the Muslim community at the mosque. These two participants expected to see more activities at this religious institution to protect the Arabic language and to benefit the children of the community. Their thoughts are reflected in the following comments:

Seriously, the role of the mosque here in Toowoomba does not offer that much, he offers sometimes, they offer some classes like two days, three days a week, people they can go to these classes, they can study, have a lecture, they can understand which is really important. But, my demand is to see more of this kind of lectures, being increasing, why not every day, why only two days a week, why only two hours, not enough. If you want people to feel the benefits of this language, you should keep them studying and learning day by day. (S8M)

The mosque educates people from religious perspectives; however, we have some Arabic language teachers here, especially for children. But it is not enough, not enough at all, very basic things, because people are volunteering without materials, without a real community guide, without a plan, you know what I mean? Just teaching them, (coughing), (sorry), 
they just they came to the mosque and taught them very basic Arabic, O.K, not supported at all. (S1OM)

\section{The benefits of Arabic and Quranic lessons - Theme 1, sub-theme 3}

All the participants stressed the reliance on the mosque to provide their children with classes in Arabic language and Quranic lessons. They all referred to the benefits of these classes in helping children maintain their language. The Muslim community of the mosque offered the Arabic and Quranic classes every weekend and during school holidays. The following excerpts illustrate participants' views:

Actually, recently they have been very active and they are doing some competitions in Quran memorizing, and doing some competition also, I think, they are holding Arabic classes here and they are very active actually. (S11M)

Yes. They run classes for children, to teach them Arabic language, so this is good. They have some difficulties because there is not enough staff to teach so many students. (S16F)

The mosque is teaching the Qur'an. So my daughter and other children go there to learn the Qur'an and Arabic. (S2OF)

This emerging theme from data analysis appears to be significant for the participants in this study as they were able to tell their stories about their experiences and challenges as they related to their language, culture and religion. The impact of the religion in the maintenance of Arabic language is one of the most important factors that has been discussed in literature and investigated in this study.

\section{Discussion}

The first observable limitation in this qualitative ethnographic inquiry is related to the generalization of the findings. The aim of this investigation was to explore the experiences and challenges of the Arabic-speaking community rather than to generalize to a larger population. The role of the religion has been found to be crucial in the field of language maintenance, according to several linguists (Baker, 2007; Clyne, 2005). This theme as a major factor contributing to the maintenance of the Arabic language includes three discussion points.

\section{The role of the religion in the maintenance of Arabic language}

The findings revealed that all the Arabic speakers referred to the crucial role that religion plays in the maintenance of their Arabic language. They reported that learning Arabic could maintain the religion and through the religion, they could maintain their Arabic. This finding is consistent with Clyne and Kipp's (1999) results who found that religion was one of the influential factors in maintaining the Arabic language among the Arabic speakers. However, their results indicated that the Arabic language was more successfully maintained by the second generation of Muslim Arabic speakers than by the second generation of non-Muslim Arabic speakers, which this research was unable to comment upon since all the participants were Muslim Arabic background speakers.

By contrast, the finding is not in line with Di Lucca et al. (2008) who reported that religion was not an indicator for the maintenance of the Arabic language within the Moroccan community in Italy.

2. The role of the mosque

According to the findings of this study, the mosque plays an important role in maintaining the Arabic language. It is not just an ordinary place for prayers and worshiping God, but also a place of learning Arabic and Islamic education. It was observed that the majority of the Arabic speakers sent their children to the Toowoomba mosque to attend Arabic and Quranic classes after school and on the weekend. The Imam of the mosque teaches the children of the community for free. Therefore, some parents donate money to the mosque's fund in return. 
These classes are held two days a week, for only two hours of teaching. It is noteworthy that there are other Muslim children from different countries who are not Arabs in origin, and they also attend the Arabic classes. The imam is the teacher who encourages the Muslim community, including the Arabic-speaking community to bring their children to learn Arabic at the mosque. The teacher at the mosque uses his teaching materials that fit well with all the learners. This finding is consistent with Gogonas' (2012) study about second-generation Arabic speakers in Athens. He found that the Arabic-speaking parents were very interested in maintaining their Arabic language by sending their children to the mosque to attend Arabic and Quranic classes. This finding is also in line with Gomaa (2011) who found that the mosque was a good replacement for the Arabic ethnic school in Durham, UK.

\section{Activities and celebrations organised by the Muslim community at the mosque}

The mosque is the gathering place for Arabic speakers and all Muslims. The role of the mosque, as a theme, was mentioned many times in the participants' statements as well as in this dissertation as an indication of its primary role in the maintenance of the Arabic language. The mosque provides several activities such as teaching Arabic to the children of the Muslim community, interpreting the Qur'an for Arabic and non-Arabic speakers, organizing events (Food Festivals and Muslim Open Day), celebrating religious events (Ramadan and Feasts), selling Halal meat and bread to the community, inviting key speakers to give lectures to people, and conducting religious marriages. All these activities have the benefit of bringing community members together where they can interact and socialize using the Arabic language. The mosque is always open to non-Arabic speakers and non-Muslims to come and learn about Islam and Muslims.

\section{Conclusion}

The findings of this study suggest that there is an overlapping connection between the religion and the Arabic language as they complete each other. The Arabic-speaking community demonstrates the contribution of their religion to the maintenance and transmission of the Arabic language to the second generation children and the vice versa. Additionally, the Muslim community of the mosque plays a crucial role in teaching Arabic to children. Their positive attitude is visible in their motivations and loyalty to maintain their community language and pass it on to their children.

Thus, the findings related to the maintenance of Arabic language in the regional city of Toowoomba are of value in enhancing the linguistic and cultural diversity in the Australian context. It may also contribute to the changing multilingual and multicultural structure of Australian society. Moreover, this study is intended to attract linguists' and educators' attention and to stimulate them to place more value on small isolated ethnolinguistic groups in their future research. At a practical level, this research may contribute to Australian multilingualism and multiculturalism by advocating the rights of small immigrant communities to be recognized. 


\section{References}

i. $\quad$ Abdalla, A., 2006. Language maintenance and shift among Arabized Malays (Makkawiyiin).. International Journal of Social Languages, Volume 182, pp. 101-115.

ii. Almubayei, D., 2007. Language and the shaping of the Arab - American identity (Doctoral dissertation, Texas University of Arlington).. [Online] Available at: https://dspace.uta.edu/bitstream/handle/10106/1198/91-119almubaye.pdf?sequence=1

iii. Australian Bureau of Statistics, 2011. Census of population and housing, Canberra: Australian Bureau of Statistics.

iv. Baker, C., 2011. Foundations of bilingual education and bilingualism. $5^{\text {th }}$ ed. s.l.:Multilingual Matters.

v. Beykont, Z., 2010. We should keep what makes us different: Youth reflections on Turkish maintenance in Australia. International journal of the sociology of language, Volume 206, pp. 93-107.

vi. Cavallaro, F., 2005. Language maintenance revisited: An Australian perspectives. The Journal of the national associ ation for bilingual education, 29(3), pp. 561-582.

vii. $\quad$ Clyne, M., 1991. Community languages. The Australian experience .. Sydney: Cambridge University Press..

viii. Clyne, M., 2005. Australia's language potential. Sydney: University of New South Wales Press.

ix. Clyne, M. \& Kipp, S., 1999. Pluricentric languages in an immigrant context: Spanish, Arabic, and Chinese. New York: Muyton DE Gruyter.

x. Creswell, J., 2014. Research design. Qualitative, quantitative, and mixed. 4th ed. Thousand Oaks: Sage Publications.

xi. Fishman, J., 1991. Reversing language shift: Theoretical and empirical foundations of assistance to threatened languages. Clevedon: Multilingual Matters.

xii. Fishman, J., 2008. Language maintenance, language shift, and reversing language shift. In: T. K. B. W. C. Ritchie, ed. The Handbook of bilingualism. s.l.:John Wiley \& Sons. , pp. 406-436.

xiii. García, M., 2003. Recent research on language maintenance.. Annual Review of Applied Linguistics, Volume 23, pp. 22-43.

xiv. Gogonas, N., 2012. Religion as a core value in language maintenance: Arabic speakers in Greece.. International Migration, 50(2), pp. 113-129.

xv. Gomaa, Y., 2011. Language maintenance and transmission: The case of Egyptian Arabic in Durham, UK.. International Journal of English Linguistics, 1(1), pp. 46-53.

xvi. Hatoss, A., 2013. Displacement Langauge Maintennace and Identity, Sudanese Refugees in Australia. [Online] Available at: http://books.google.com.au/books?id=phFAgAAQBAJ \&printsec $=$ frontcover\&source $=$ gbs ge summary $r \& c a d=0 \# v=$ onepage $\&$ $q \& f=$ false

xvii. Holmes, J., 2013. An introduction to sociolinguistics. 4th ed. s.l.:Pearson Education Limited.

xviii. Johnson, B. \& Christensen, L., 2012. Educational research: Quantitative, qualitative, and mixed approaches. 4th ed. New York: Sage Publications.

xix. Lucca, L. D., Masiero, G. \& Pallotti, G., 2008. Language socialisation and language shift in the $1 \mathrm{~b}$ generation: A study of Moroccan adolescents in Italy.. International Journal of Multilingualism, 5(1), pp. 53-72.

xx. Martin, N., 2009. Arab American parents' attitudes toward their children's heritage language maintenance and language practices (Master's thesis, School of Education, Chapel Hill, America).. [Online] Available at: https://cdr.lib.unc.edu/indexablecontent?id=uuid:15b293fq982f-445fgadd-400e48ad38b4\&ds=DATA FILE 
xxi. Rubino, A., 2010. Multilingualism in Australia: Reflections on current and future research trends.. [Online] Available at: http://www.nla.gov.au/openpublish/index.php/aral/ article/viewFile/2050/ 2433

xxii. Sehlaoui, A., 2008. Language learning, heritage, and literacy in the USA: The case of Arabic. Language, Culture and curriculum, 21(3), pp. 280-291. 